\title{
ECOLOGICAL LIFE HISTORY OF BAETISCA BERNERI TARTER AND KIRCHNER FROM A WEST VIRGINIA STREAM (EPHEMEROPTERA: BAETISCIDAE)
}

\author{
By William R. Morris, Dwight L. Chaffee \\ AND DONALD C. TARTER ${ }^{1}$
}

The primary objective of this investigation was to study the ecological life history of the mayfly Baetisca berneri Tarter and Kirchner in Laurel Fork, Mingo Co., West Virginia. Many authors, including Say (1839), Traver (1931), Needham et al. (1935), Berner (1940, 1955), Edmunds (1960), Schneider and Berner (1963), Pescador and Peters (1971, 1974), Lehmkuhl (1972), Tarter and Kirchner (1978) and Chaffee and Tarter (1979), have reported studies on the taxonomy and ecology of the genus Baetisca.

\section{TAXONOMY AND DisTRIBUTION}

The genus Baetisca, established by Walsh (1862), is the only member of the family Baetiscidae. Presently, there are 12 species of Baetisca known from the United States (Edmunds et al., 1976; Tarter and Kirchner, 1978). Tarter and Kirchner (1978) described the new species $B$. berneri and reported its distribution from West Virginia and Virginia.

\section{Materials AND Methods}

The study site is Laurel Fork of Pigeon Creek of Tug Fork of the Big Sandy River in Mingo County, West Virginia. It lies $2.4 \mathrm{~km}$ southeast of Dingess and $3.2 \mathrm{~km}$ northeast of Laurel Lake. The stream width averages $4.6 \mathrm{~m}$ and the water depth ranged from 2.5 to $74 \mathrm{~cm}$. The substrate is sand, gravel and rocks. The more dominant species of the riparian forest are Red Maple, Acer rubrum L.; Smooth Alder, Alnus serrulata (Ait.) Willd.: Black Birch, Betula lenta L.; Rhododendron, Rhododendron maimum L.; and Eastern Hemlock, Tsuga canadensis (L.) Carr.

\footnotetext{
${ }^{1}$ Dept. of Biological Sciences, Marshall Univ., Huntington, W. Va. 25701
}

Manuscript received by the editor August 13, 1980. 
Monthly samples of nymphs were taken from December, 1974, to November, 1975. The bottom substrate was disturbed and a hand dredge (mesh size, $0.75 \mathrm{~mm}^{2}$ ) was placed directly downstream to collect the drifting nymphs. Except for the rearing experiment, all nymphs were preserved in 70 percent ethanol.

The water quality parameters were measured monthly throughout the study period with a Hach kit, Model AL-36-WR. Dissolved oxygen $(\mathrm{mg} / 1)$, carbon dioxide $(\mathrm{mg} / \mathrm{l})$, bicarbonate alkalinity $(\mathrm{mg} / 1$ $\left.\mathrm{CaCO}_{3}\right)$, total hardness $\left(\mathrm{mg} / 1 \mathrm{CaCO}_{3}\right)$ and $\mathrm{pH}$ were recorded. Water temperature was measured each month with a Taylor thermometer placed near the surface of the water.

Length-frequency distributions were recorded for the nymphs in order to help determine the duration of the life cycle. The body length (from the base of the caudal filaments to the front margin of the head excluding the genal spines) was measured under a Bausch and Lomb dissecting microscope with a Vernier caliper to the nearest $0.1 \mathrm{~mm}$. Both sexes were grouped together and placed in one millimeter size groups.

A population range diagram was used to show the monthly variation in nymphal head widths. The head width measurements, excluding the eyes, were made with an ocular micrometer mounted in a dissecting microscope to the nearest $0.05 \mathrm{~mm}$. Males and females for each month were separated and the range, mean, standard deviation and standard error of the mean were calculated for each group.

Sex determination of the nymphs was made by the position and shape of the eyes. The eyes of the male were closer together and more angular toward each other than those of the female. A chi-square test was applied to determine any significant departure from the expected $1: 1$ ratio at the 0.05 confidence level.

The foregut content of five nymphs was analyzed for each month. The head was severed from the body with micro-dissecting scissors and an incision was made along the midline of the ventral body surface to the center of the abdomen. The foregut was removed and its contents emptied onto a microscope slide with water as the mounting medium. The contents were viewed under a microscope with a Whipple ocular grid at $430 \times$ magnification. Ten fields or grids were selected at random and counted for each nymph. Values were given according to the number of small grid squares covered by the individual food item. Organic and mineral detritus were grouped 
together. Diatoms and filamentous algae were grouped as separate catgories.

A habitat preference study on nymphs was designed. A tray $(61 \times$ $30.5 \times 6.5 \mathrm{~cm}$ ) was filled with $2.5 \mathrm{~cm}$ of water from the study area. The bottom of the tray was filled with three different substrates. Onethird was filled with sand only, one-third with sand, gravel and small rocks and one-third with sand and leaf litter. The water was constantly aerated with a Hush air pump and the tray was placed in a controlled chamber which kept the water temperature at $11 \mathrm{C}$. The nymphs were then released at different places in the tray. After 12 hours of darkness, the tray was checked for the location of the nymphs. The entire tray was then illuminated with a light placed so that it shone equally on each area. After 12 hours, the nymphal positions were checked. The second part of the experiment involved shining the light directly on one area, while the other two areas were covered. After 12 hours, the position of the nymphs was recorded and another area was illuminated. The entire experiment was then replicated.

Direct egg counts of four subimagos and three imagos from lab rearings were made. These adults had been preserved in 70 percent ethanol. The body cavity was opened with micro-dissecting scissors and the eggs were carefully extruded into a culture dish and counted under a Bausch and Lomb dissecting microscope. The diameter of 50 eggs per female was measured with an ocular micrometer mounted in a microscope to the nearest $0.01 \mathrm{~mm}$.

\section{Results AND Discussion}

Stream Environment. - The water quality of Laurel Fork was excellent for aquatic life. Dissolved oxygen concentrations ranged from 10 (June-August) to $14 \mathrm{mg} / \mathrm{l}$ (February and April); the mean was $11.9 \mathrm{mg} / 1$. Carbon dioxide was $5 \mathrm{mg} / 1$ during all months except November $(10 \mathrm{mg} / \mathrm{l})$. Total hardness ranged from $34.2 \mathrm{mg} / 1$ in February, March and October to $68.4 \mathrm{mg} / \mathrm{l}$ in May and June; the mean was $49.7 \mathrm{mg} / 1$. Bicarbonate alkalinity values ranged from 13.7 to $51.3 \mathrm{mg} / 1$. February and May-September, respectively; the mean was $37.6 \mathrm{mg} / 1$. The hydrogen ion concentration $(\mathrm{pH})$ ranged from 7.5 to 8.5 ; the mean was 8.1 . The mean annual water temperature was $11.6 \mathrm{C}$; the range was 2.8 to $22.0 \mathrm{C}$, January and August, respectively. 


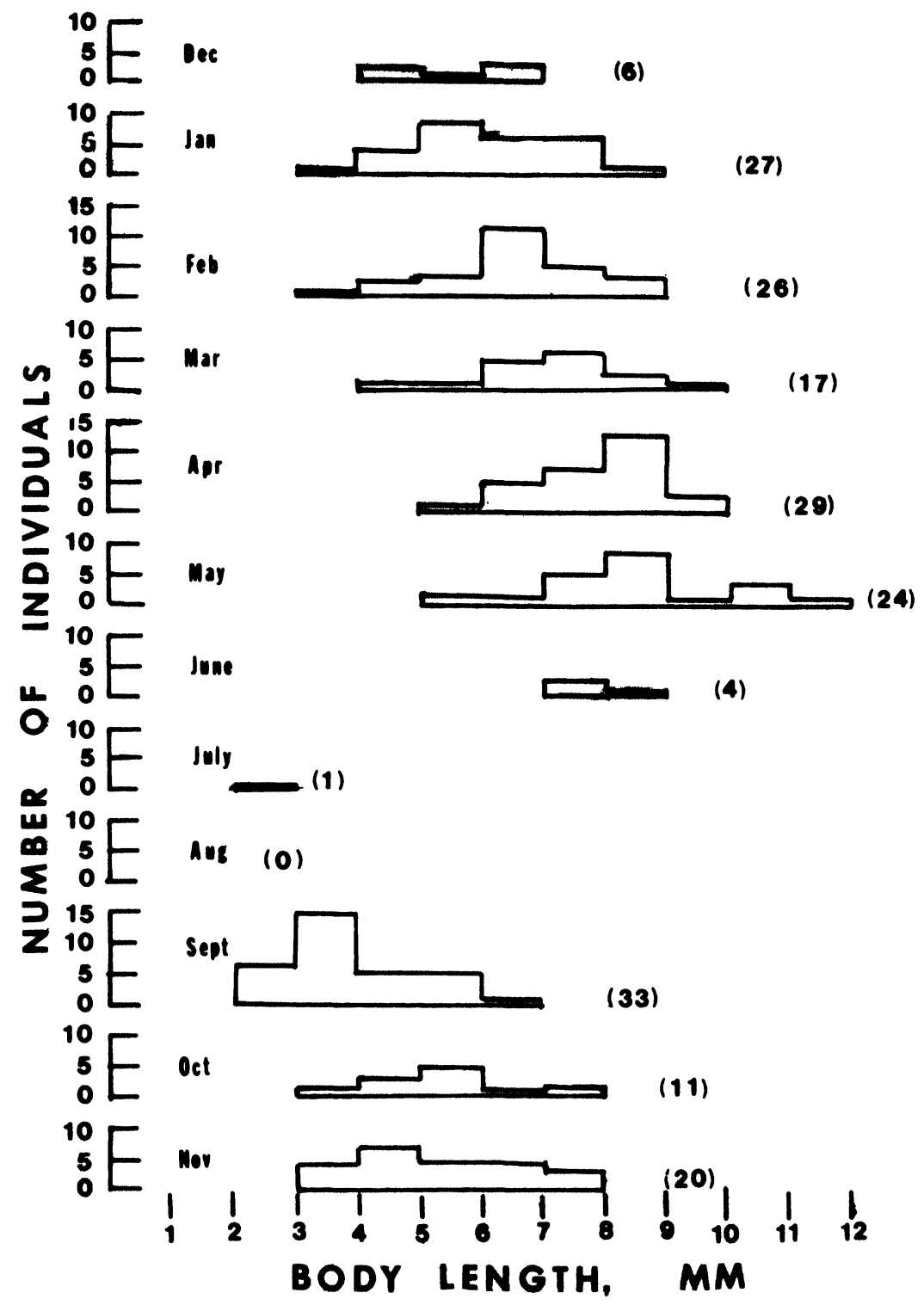

Figure 1. Size-class distribution of nymphs of Baetisca berneri based on body length. The number of individuals each month is in parenthesis. 


\section{NYMPHAL STAGE}

Size-Class Distribution. - Length-frequency distributions indicate a univoltine life cycle (Figure 1). The smallest nymph $(2.1 \mathrm{~mm})$ was collected in July and the largest nymph $(11.2 \mathrm{~mm})$ was taken in May. The increasing monthly progression of the size class and the total disappearance of large nymphs in the July sample indicated a one year life cycle. Nymphs hatched as early as July and progressed in size until late May or June when they emerged. Numerous nymphal skins were found on stones less than $5 \mathrm{~cm}$ from the waters edge or water lies in mid-June. The population range diagram, based on nymphal head widths, is presented in Figure 2. The smallest head width occurred in July $(0.7 \mathrm{~mm})$ and the largest head width occurred in May $(3.1 \mathrm{~mm})$.

Traver (1931) collected Baetisca carolina in North Carolina in March and emergence occurred in April and May in the laboratory. Small nymphs of $B$. callos $a$ in West Virginia were found as early as August (Traver, 1931). Traver (1937) found skins of $B$. thomsenae (= carolina) in Florida in May and June. Berner (1955) reported laboratory emergence of $B$. obesa from early March to early April in

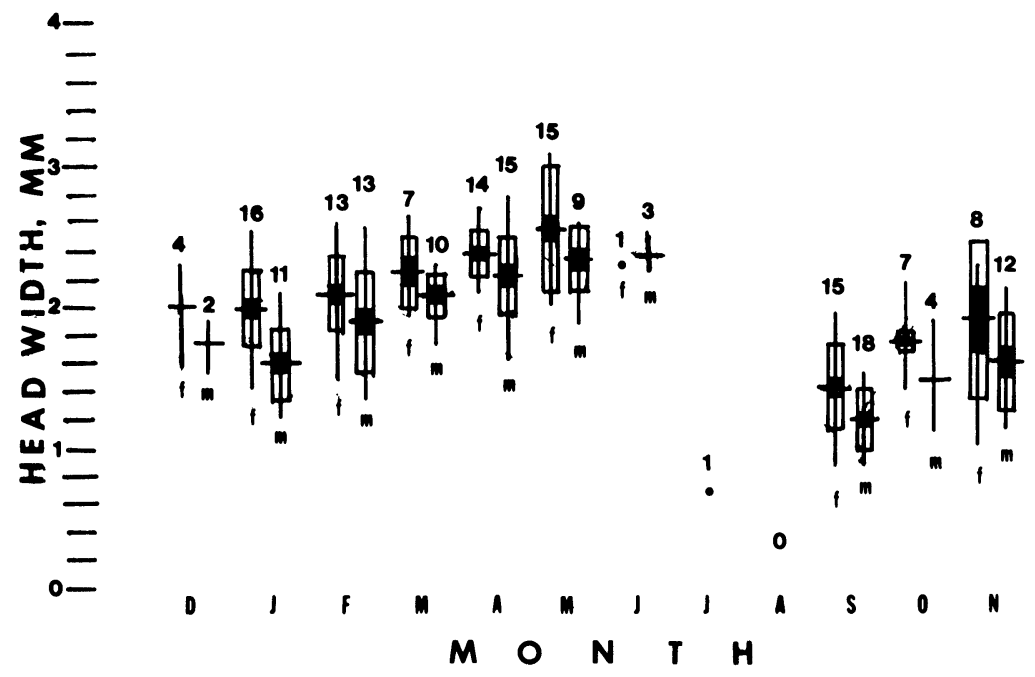

Figure 2. Population range diagram of nymphs of $B$. berneri based on head widths. Vertical lines $=$ range, horizontal lines $=$ mean, open rectangles $=$ one standard deviation, closed rectangles $=$ one standard error of the mean, $\mathrm{m}=$ male, and $f=$ female. 
southern Georgia and northern Florida. Pescador and Peters (1971) found extremely small nymphs of $B$. becki in Florida in September and nymphs collected in April emerged in May in the laboratory. Chaffee and Tarter (1979), in studying the life history of B. bajkovi in West Virginia, reported a univoltine life cycle. The smallest nymphs were found in July with the largest nymphs collected in the middle of May. Emergence occurred in May. Lehmkuhl (1972) studied the life cycle of B. bajkovi in Canada and found a one year life cycle. Eggs hatched in early September and mature nymphs emerged in the laboratory in June and July. Pescador and Peters (1974) observed a one year life cycle for B. rogersi in Florida. Nymphs were first found in September and emerged from April to July. Berner (1955) reported a different account for B. escambiensis. He collected mature nymphs in October from a Florida river and they emerged in the laboratory in November.

Sex Ratio. -The expected 1:1 sex ratio was observed for $B$. berneri. Ninety-seven males and 100 females were collected during the study period. The difference was not significant at the 0.05 confidence level.

Foregut Analysis.-The foregut contents of the nymphs for the study period are given in Table 1 . The main constituent was always detritus, with diatoms usually abundant, and filamentous algae present to a smaller degree. Most abundant diatoms were Synedra sp., Cymbella sp., Nitzschia sp., Navicula sp. and Gomphonema sp.

Table 1. Relative abundance of foregut contents of Baetisca berneri nymphs from Laurel Fork, Mingo County, West Virginia.

\begin{tabular}{lcrcc}
\hline & \multicolumn{4}{c}{ Filamentous } \\
Month & Detritus & $\begin{array}{c}\text { Diatoms } \\
\text { Algae }\end{array}$ & $\begin{array}{c}\text { No. of } \\
\text { Foreguts }\end{array}$ \\
\hline Sept. & $(\%)$ & $(\%)$ & $(\%)$ & 5 \\
Oct. & 88.0 & 8.0 & 4.0 & 5 \\
Nov. & 72.0 & 26.0 & 2.0 & 5 \\
Dec. & 70.0 & 29.0 & 1.0 & 5 \\
Jan. & 64.0 & 35.0 & 1.0 & 5 \\
Feb. & 75.0 & 20.0 & 5.0 & 5 \\
Mar. & 87.0 & 10.0 & 3.0 & 5 \\
Apr. & 86.0 & 6.0 & 6.0 & 5 \\
May & 68.0 & 30.0 & 2.0 & 5 \\
June & 53.0 & 36.0 & 11.0 & 2 \\
\hline Mean & 80.0 & 19.0 & 1.0 & 47 \\
\hline
\end{tabular}


Other recognizable diatoms were Fragilaria sp., Meridion sp., Cocconeis sp. and Achnanthes sp. Diatom abundance was greatest during April and May and October-December. The nymphs collected during May had the largest amount of filamentous algae. One desmid was found in the study (Straurastrum sp.).

Pescador and Peters (1974) conducted a similar study on B. rogersi and the results corresponded with those in this study. However, it must be pointed out that their particles were counted on the basis of number present and not on the area of small grid squares covered. The nymphs of $B$. bajkovi are detritivorous with almost two-thirds (65.3\%) of the diet composed of plant and leaf detritus (Chaffee and Tarter, 1979).

Habitat Preference. - The preference was for the sand, gravel and small stone substrate during all light or all dark conditions. A slight preference for sand and leaf litter over sand only was shown. When the light was directed to one substrate only, the majority of nymphs moved to that substrate.

Pescador and Peters (1974) reported similar results for B. rogersi. Lehmkuhl (1972) found that B. bajkovi preferred a stony or grassy substrate to a sand only substrate.

\section{ADULT STAGE}

Rearing Observations. - Nymphs were reared in the laboratory beginning April 23 and emerged from May 7 to the end of May. All subimagos emerged betwen $10 \mathrm{AM}$ and $2 \mathrm{PM}$ and all imagos emerged approximately 24 hours later.

Emergence of $B$. bajkovi adults occurred in the laboratory from May 2 to May 26 (Chaffee and Tarter, 1979). All subimagos emerged betwen $9 \mathrm{AM}$ and $7 \mathrm{PM}$ with the imagos emerging 13 to 25 hours later. Emergence data for other members of the genus Baetisca were reported by Traver (1931 and 1937), Berner (1940 and 1955) and

Pescador and Peters (1974) found that duration of the subimago stage of $B$. rogersi is dependent on water temperature. The warmer temperatures produce a shorter subimago stage.

Fecundity. - Egg counts for B. berneri ranged from 1001 to 2375; the mean number of eggs per female was 1899. Egg counts were reported for B. rogersi (Pescador and Peters, 1974). The range was from 1500 to 2727 eggs; the mean number of eggs per individual was 2168. Ovarian egg counts for B. bajkovi ranged from 1508 to 3158; the mean was 2361 (Chaffee and Tarter, 1979). 
Egg Size and Morphology. - The mean egg diameter was $0.18 \mathrm{~mm}$; individual eggs ranged from 0.13 to $0.21 \mathrm{~mm}$. The eggs were sculptured and mostly round, and were olive green in color.

Smith (1935) reported the egg diameter of $B$. obesa and B. carolina to be $0.18 \mathrm{~mm}$ and reported them to be nearly spherical and smooth on the surface. Pescador and Peters (1974) reported different sizes and shapes for newly laid eggs of $B$. rogersi and for eggs 3-5 hours after oviposition (mature eggs). Newly laid eggs which would correspond to those in this study were $0.1-0.2 \mathrm{~mm}$ in diameter, slightly oblong, and sculptured. The mature eggs were rounded, smooth and $0.2-0.3 \mathrm{~mm}$ in diameter.

\section{REFERENCES}

Berner, L. 1940. Baetisca rogersi, a new mayfly from northern Florida. Can. Ent. 62:156-160.

1955. The southeastern species of Baetisca (Ephemeroptera: Baetiscidae). Quart. J. Fla. Acad. Sci. 18:1-19.

Chaffee, D. L., AND D. C. TARTER. 1979. Life history and ecology of Baetisca bajkovi Neave in Beech Fork of Twelvepole Creek, Wayne County, West Virginia (Ephemeroptera: Baetiscidae). Psyche 86(1):53-61.

Edmunds, G. F. 1960. The mayfly genus Baetisca in western North America. PanPacific Ent. 36(2): 102-104.

, S. L. Jensen, ANd L. Berner. 1976. The mayflies of North and Central America. Univ. of Minnesota Press, Minneapolis, Minn. 330 pp.

LehmKunL, D. M. 1972. Baetisca (Ephemeroptera: Baetiscidae) from the western interior of Canada with notes on the life cycle. Can. J. Zool. 50(7);1015-1017.

Needham, J. G., J. R. Traver, and Y. Hsu. 1935. The Biology of Mayflies, Comstock Publishing Co., Inc., Ithaca, N. Y. 759 pp.

Pescador, M. L., And W. L. Peters. 1971. The imago of Baetisca becki Schneider and Berner. Fla. Ent. 54(4):329-334.

1974. The life history and ecology of Baetisca rogersi Berner (Ephemerop tera: Baetiscidae). Bull. Fla. State Mus. Biol. Sci. 17(3):151-209.

SAY, T. 1839. Descriptions of new North American neuropterous insects and observations on some already described. J. Acad. Nat. Sci. Phila. 8:9-46.

SChNeIDER, R. F., AND L. Berner. 1963. A new southeastern species of Baetisca (Ephemeroptera: Baetiscidae). Fla. Ent. 46:183-187.

SмIтH, O. R. 1935. Chapter VII. The eggs and egg-laying habits of North American mayflies. pp. 67-89. In: Needham, J. G., J. R. Traver, and Y. Hsu. 1935. The Biology of Mayflies with a systematic account of North American Species. Comstock Publ. Co., Inc., Ithaca, N. Y. 759 pp.

TARTER, D. C., AND R. F. Kirchner. 1978. A new species of Baetisca from West Virginia (Ephemeroptera: Baetiscidae). Ent. News 89(9-10):209-213.

Traver, J. R. 1931. The ephemerid genus Baetisca. J. N. Y. Ent. Soc. 39:45-66. 1937. Notes on mayflies of the southeastern United States. J. Eli. Mitch. Soc. 53:27-87. 
W ALSH, B. D. 1862. List of Pseudoneuroptera of Illinois, contained in the cabinet of the writer, with description of over forty new species and notes of their structural affinities. Proc. Acad. Nat. Sci. Phila. 13:361-402. 

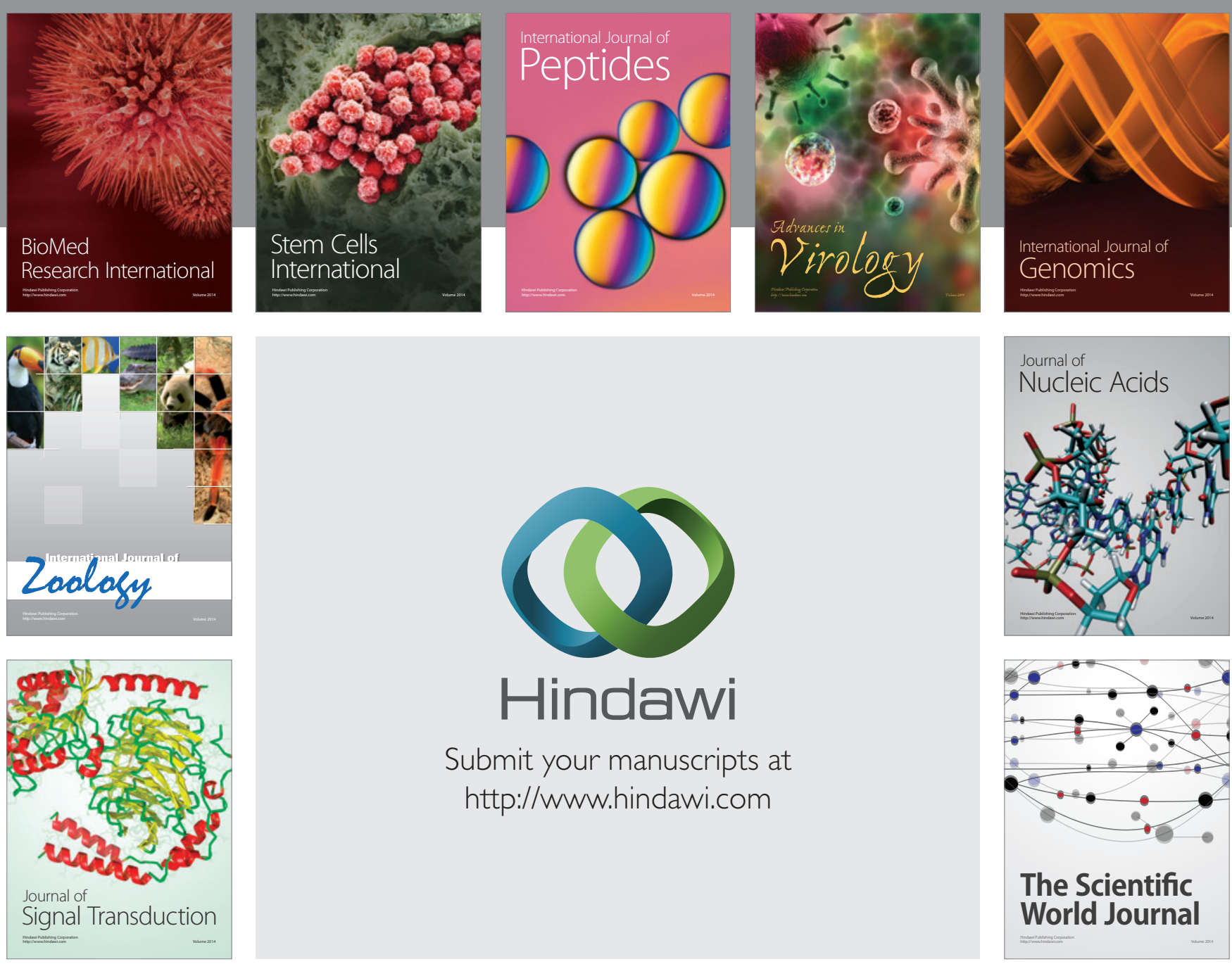

Submit your manuscripts at

http://www.hindawi.com
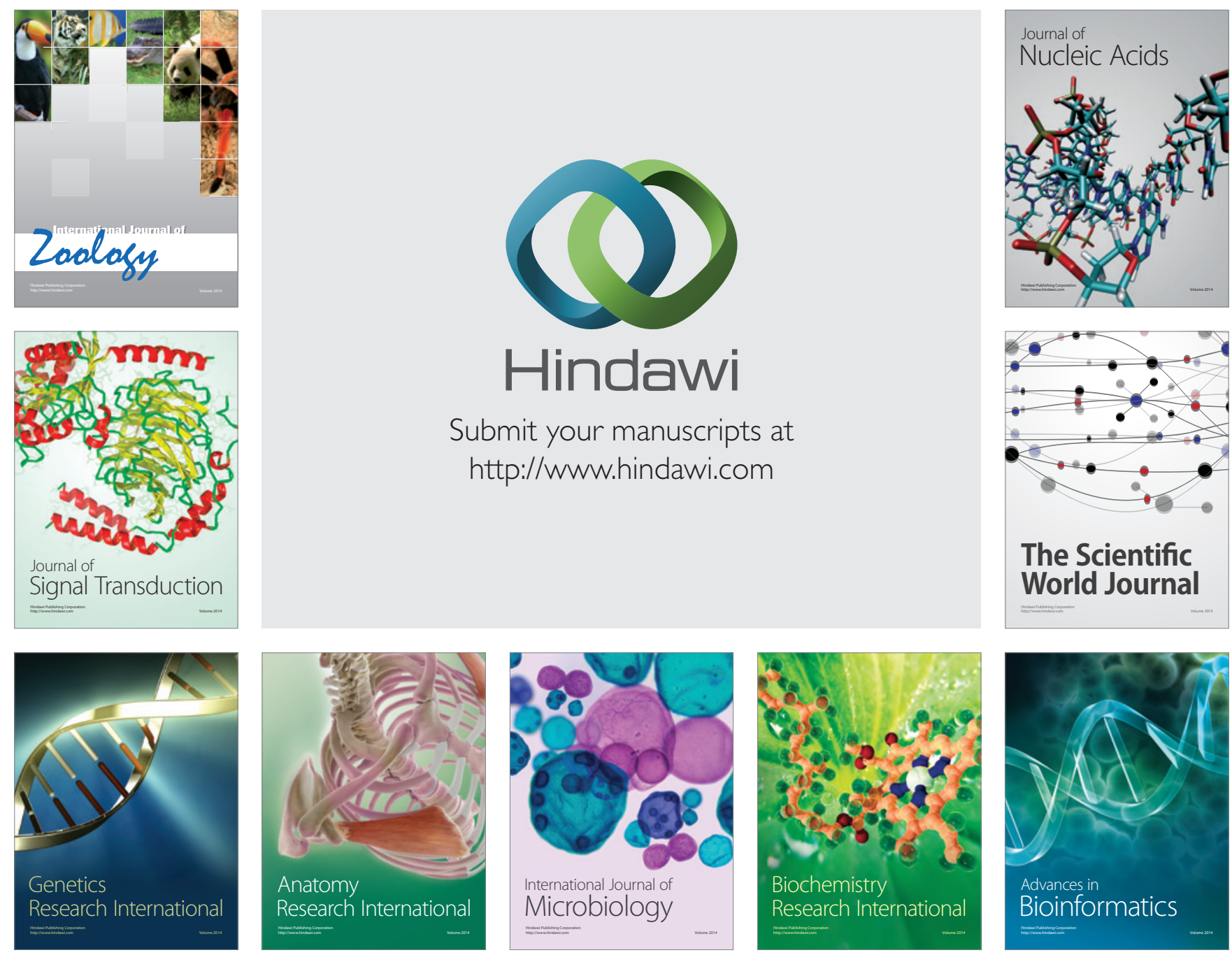

The Scientific World Journal
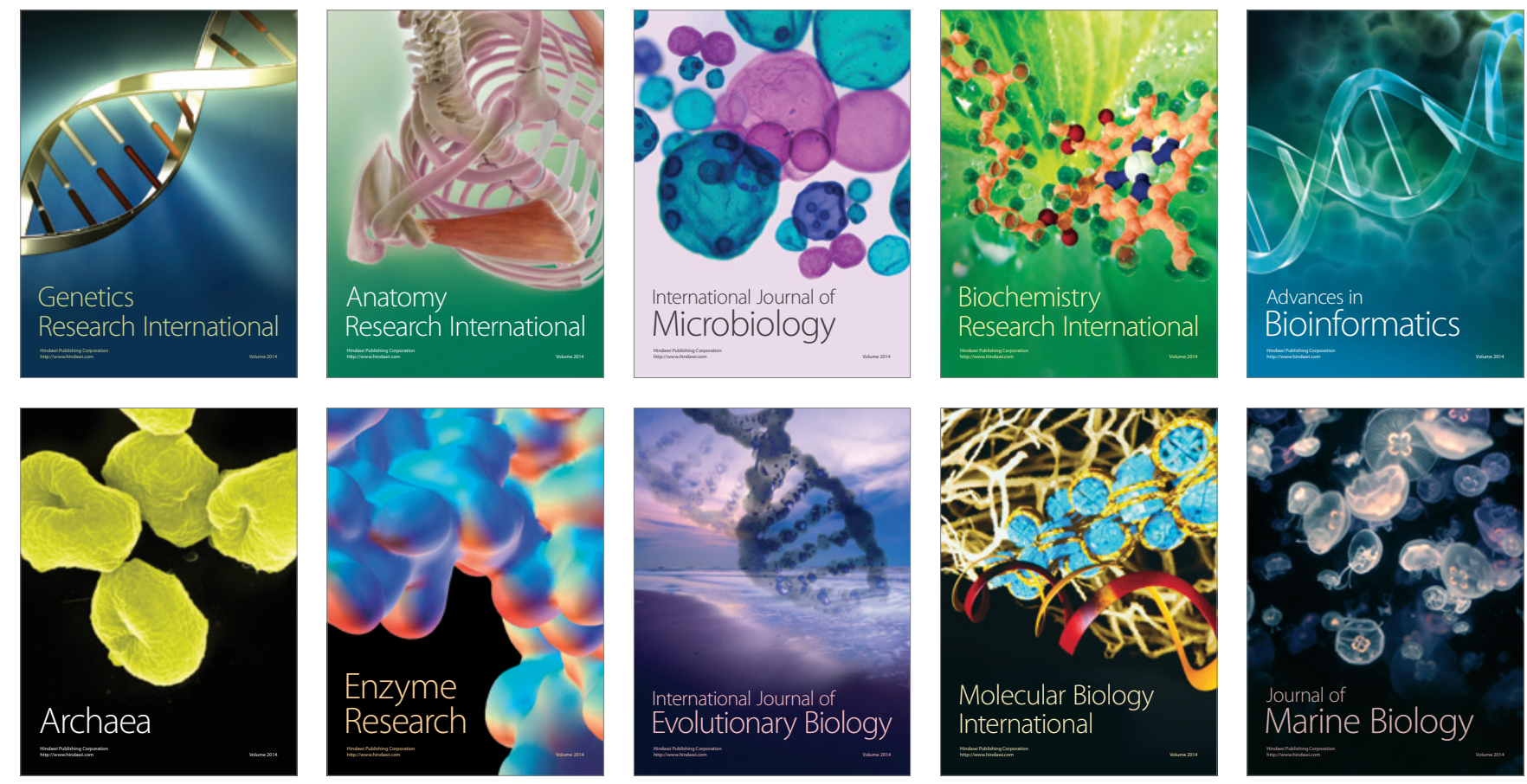